\title{
PENGARUH KUALITAS PRODUK DAN HARGA TERHADAP VOLUME PENJUALAN BERAS PREMIUM PERUM BULOG KANTOR CABANG BIAK
}

\author{
Krismiyati 1 \\ Krisyati88@gmail.com \\ Sri Handayani ${ }^{2}$ \\ shanday@gmail.com \\ Moh. Syukur 3 \\ syukur.moh@gmail.com

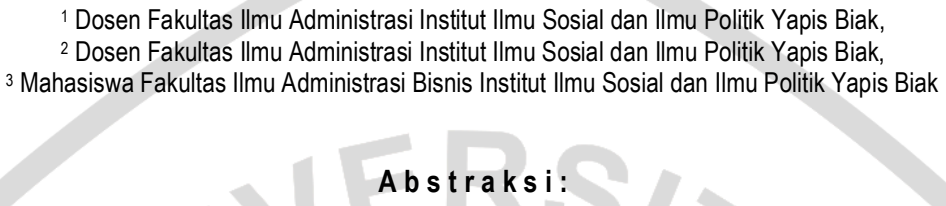

Perusahaan Umum (Perum BULOG) adalah badan usaha milik negara yang bergerak di bidang logistik pangan. Ruang lingkup bisnisnya meliputi usaha logistik/pergudangan, survei dan pemberantasan hama, usaha angkutan, penyedia karung plastik, perdagangan komoditi pangan dan usaha eceran. Sebagai perusahaan yang mengemban tugas publik dari pemerintah, Perum BULOG mengadakan kegiatan menjaga harga dasar pembelian untuk gabah, stabilisasi harga khususnya harga pangan pokok, pengelolaan stok pangan dan penyaluran beras. Tujuan Penelitian ini adalah untuk mengetahui Pengaruh kualitas Produk dan Harga terhadap volume penjualan khususnya beras Premium diPerum BULOG Biak. Perum BULOG menjual beras kualitas premium yang ditujukan untuk komersil. Kualitas yang berbeda ini memiliki harga yang berbeda pula. Hal ini tentu berpengaruh pada volume penjualan karena minat masyarakat yang berbeda terhadap masing - masing kualitas dan harga beras. Semakin tinggi volume penjualan maka beras yang diserap Perum BULOG akan semakin banyak sehingga dapat menampung hasil panen petani secara maksimal. Metode penelitian adalah metode penelitian Kuantitatif , Populasi dalam penelitian ini adalah laporan penjualan komoditi di Perum BULOG Kantor Cabang Biak. Kriteria pemilihan sampel adalah laporan penjualan beras premium komersil di Perum BULOG Kantor Cabang Biak Bulan Januari 2020 sampai dengan bulan Juni 2020. Hasil penelitian menunjukan bahawa Kualitas Produk dan Harga secara simultan berpengaruh terhadap Volume Penjualan dimana angka signifikansi sebesar 0,000 lebih kecil dari tingkat signifikansi 0,05 . Kualitas Produk secara parsial berpengaruh terhadap Volume Penjualan dimana angka signifikansi sebesar 0,002 lebih kecil dari tingkat signifikansi 0,05.

Kata Kunci : Kualitas Produk, Penjualan, Beras Premium.

\section{PENDAHULUAN}

\section{A. Latar Belakang}

Tanaman pangan yang sampai saat ini dianggap sebagai komoditi terpenting dan strategis bagi perekonomian adalah padi karena selain merupakan bagian makanan pokok bagi penduduk Indonesia. produksi padi bersifat sangat musiman, sementara itu komsumsi terus meningkat karena pertumbuhan populasi dan peningkatan pendapatan. Salah satu komoditas pangan yang mempunyai peranan penting bagi masyarakat maupun pemerintah Indonesia adalah beras. Irawan (2005:108) mengatakan beras merupakan komponen pangan (bahan makanan) terbesar bagi penduduk yang selain jumlahnya banyak laju pertumbuhannya pun relatif masih tinggi. Selain itu, permintaan dan konsumsi beras perkapita cenderung meningkat dari tahun ke tahun, kegagalan pemerintah dalam menyediakan dan mengendalikan persediaan komoditas ini dipastikan akan memicu kerusuhan sosial. BULOG telah mengalami perubahan menjadi bentuk perusahaan umum (Perum), namun BULOG tetap dapat menjalankan tugas publik yang dibebankan oleh pemerintah terutama dalam pengamanan harga gabah, pendistribusian beras untuk masyarakat miskin yang rawan pangan, pengadaan dan penyaluran beras pada saat terjadinya fluktuasi harga, dan kepentingan publik lainnya dalam upaya mengendalikan gejolak harga.

Selain masih mengemban beberapa tugas publik, BULOG yang sekarang juga berorientasi pada kegiatan komersil sebagaimana perusahaan lainnya (Silsia, 2007:2). Sejak tahun 2003 sampai sekarang, berdasarkan peraturan pemerintah No.7/2003 Perum BULOG ditugaskan pemerintah untuk melaksanakan tugas publik di bidang pembangunan pemberasan nasional yaitu melaksanakan kebijakan pembelian gabah/beras dalam negeri dengan ketentuan harga pembelian 
pemerintah (HPP). Kegiatan ini diwujudkan dalam bentuk pengadaan gabah dan beras dalam negeri oleh Perum BULOG, menyediakan dan menyalurkan beras bersubsidi bagi kelompok masyarakat berpendapatan rendah, menjaga stabilitas harga beras, menanggulangi keadaan darurat, bencana dan rawan pangan. Kegiatan ketiga dilaksanakan Perum BULOG dalam bentuk pengelolaan cadangan beras pemerintah yang selanjutnya disebut CBP. Persaingan dalam dunia bisnis semakin ketat dan tidak dapat dihindari. Pelaku-pelaku bisnis selalu memiliki berbagai cara agar produknya dapat unggul dari produk lain. Agar produknya dapat bersaing, maka kualitas produk harus ditingkatkan sehingga volume penjualan juga dapat meningkat. Setiap produsen harus bisa menjaga kualitas produk dan menentukan harga yang tepat agar mendapat kepercayaan dan loyalitas dari konsumen, jika produk yang dijual memiliki kualitas yang bagus dengan harga yang sesuai maka diharapkan mampu bersaing dengan para pesaingnya. Perusahaan Umum (Perum BULOG) adalah badan usaha milik negara yang bergerak di bidang logistik pangan. Ruang lingkup bisnisnya meliputi usaha logistik/pergudangan, survei dan pemberantasan hama, usaha angkutan, penyedia karung plastik, perdagangan komoditi pangan dan usaha eceran. Sebagai perusahaan yang mengemban tugas publik dari pemerintah, Perum BULOG mengadakan kegiatan menjaga harga dasar pembelian untuk gabah, stabilisasi harga khususnya harga pangan pokok, pengelolaan stok pangan dan penyaluran beras. Perum BULOG merupakan salah satu BUMN yang bertugas untuk mengelola bahan pangan, seperti beras. tidak hanya CBP (Cadangan Beras Pemerintah), Perum BULOG juga menjual beras kualitas premium yang ditujukan untuk komersil. Kualitas yang berbeda ini memiliki harga yang berbeda pula. Hal ini tentu berpengaruh pada volume penjualan karena minat masyarakat yang berbeda terhadap masing - masing kualitas dan harga beras. Semakin tinggi volume penjualan maka beras yang diserap Perum BULOG akan semakin banyak sehingga dapat menampung hasil panen petani secara maksimal. Masalah spesifik yang dihadapi Perum BULOG Kantor Cabang Biak:

1. Banyak brand pesaing yang lebih dulu terkenal.

2. Brand Perum BULOG untuk beras premium sangatlah baru dan belum terlalu terkenal di masyarakat Biak Numfor.

3. Kontinuitas produk (barang tidak selalu ada dan butuh waktu sehingga barang tersedia kembali)

Data penjualan beras komersil Perum BULOG Kantor Cabang Biak mulai bulan Januari 2020 hingga bulan Juni 2020 dapat dilihat pada Tabel 1 laporan penjualan beras premium Perum BULOG Kantor Cabang Biak.

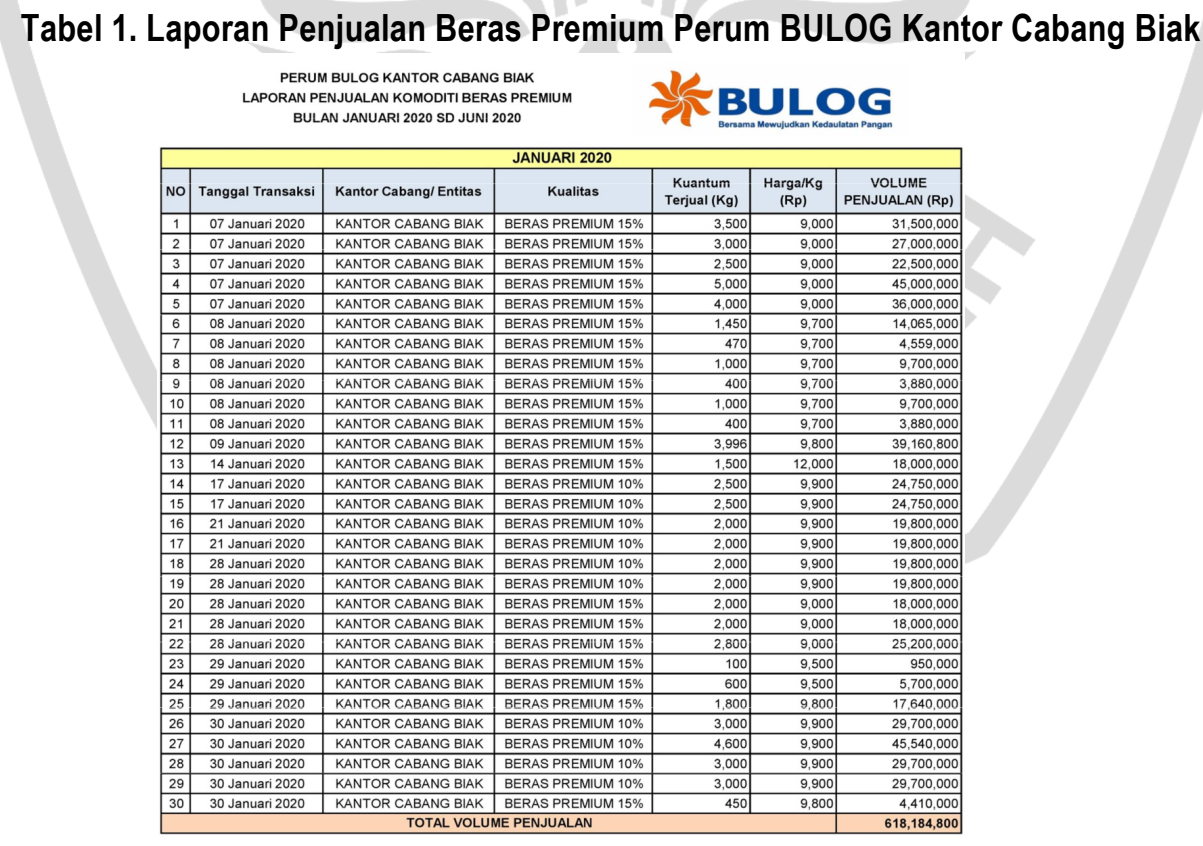




\begin{tabular}{|c|c|c|c|c|c|c|}
\hline \multicolumn{7}{|c|}{ FEBRUARI 2020} \\
\hline No & Tanggal Transaksi & Kantor Cabang/ Entitas & Kualitas & $\begin{array}{c}\text { Kuantum } \\
\text { Terjuai (Kg) }\end{array}$ & $\begin{array}{c}\mathrm{Harga} / \mathrm{Kg} \\
\text { (Rp) }\end{array}$ & $\begin{array}{c}\text { VOLUME } \\
\text { PENJUUALAN (RP) }\end{array}$ \\
\hline 1 & 03 Februari 2020 & KANTOR CABANG BIAK & BERAS PREMIUM $15 \%$ & 130 & 9,500 & $1,235,000$ \\
\hline 2 & 03 Februari 2020 & KANTOR CABANG BIAK & BERAS PREMIUM $15 \%$ & 207 & 9,800 & $2,028,600$ \\
\hline 3 & 03 Februari 2020 & KANTOR CABANG BIAK & BERAS PREMIUM $10 \%$ & 4,370 & 10,500 & $45,885,000$ \\
\hline 4 & 03 Februari 2020 & KANTOR CABANG BIAK & BERAS PREMIUM $10 \%$ & 400 & 9,900 & $3,960,000$ \\
\hline 5 & 04 Februari 2020 & KANTOR CABANG BIAK & BERAS PREMIUM $15 \%$ & 180 & 9,800 & $1,764,000$ \\
\hline 6 & 12 Februari 2020 & KANTOR CABANG BIAK & BERAS PREMIUM $10 \%$ & 2,000 & 9,900 & $19,800,000$ \\
\hline 7 & 12 Februari 2020 & KANTOR CABANG BIAK & BERAS PREMIUM $10 \%$ & 3,000 & 9,900 & $29,700,000$ \\
\hline 8 & 17 Februari 2020 & KANTOR CABANG BIAK & BERAS PREMIUIM $15 \%$ & 279 & 9,800 & $2,734,200$ \\
\hline 9 & 17 Februari 2020 & KANTOR CABANG BIAK & BERAS PREMIUM $15 \%$ & 2,000 & 9,000 & $18,000,000$ \\
\hline 10 & 17 Februari 2020 & KANTOR CABANG BIAK & BERAS PREMIUM $15 \%$ & 3,000 & 9,000 & $27,000,000$ \\
\hline 11 & 17 Februari 2020 & KANTOR CABANG BIAK & BERAS PREMIUM $15 \%$ & 2,000 & 9,000 & $18,000,000$ \\
\hline 12 & 24 Februari 2020 & KANTOR CABANG BIAK & BERAS PREMIUM $10 \%$ & 1,250 & 9,900 & $12,375,000$ \\
\hline 13 & 24 Februari 2020 & KANTOR CABANG BIAK & BERAS PREMIUM $10 \%$ & 2,000 & 9,900 & $19,800,000$ \\
\hline 14 & 25 Februari 2020 & KANTOR CABANG BIAK & BERAS PREMIUM $10 \%$ & 2,800 & 9,900 & $27,720,000$ \\
\hline 15 & 26 Februari 2020 & KANTOR CABANG BIAK & BERAS PREMIUM $15 \%$ & 5,000 & 9,000 & $45,000,000$ \\
\hline 16 & 27 Februari 2020 & KANTOR CABANG BIAK & BERAS PREMIUM $15 \%$ & 260 & 12,000 & $3,120,000$ \\
\hline 17 & 27 Februari 2020 & KANTOR CABANG BIAK & BERAS PREMIUM $15 \%$ & 260 & 12,000 & $3,120,000$ \\
\hline \multicolumn{6}{|c|}{ TOTAL VOLUME PENJUALAN } & $281,241,800$ \\
\hline
\end{tabular}

\begin{tabular}{|c|c|c|c|c|c|c|}
\hline \multicolumn{7}{|c|}{ MARET 2020} \\
\hline NO & Tanggal Transaksi & Kantor Cabang/ Entitas & Kualitas & $\begin{array}{l}\text { Kuantum } \\
\text { Terjual (Kg) }\end{array}$ & $\begin{array}{c}\text { Harga/Kg } \\
(\text { Rp) }\end{array}$ & $\begin{array}{c}\text { VOLUME } \\
\text { PENJUALAN (Rp) }\end{array}$ \\
\hline 1 & 02 Maret 2020 & KANTOR CABANG BIAK & BERAS PREMIUM $15 \%$ & 5,000 & 9,000 & $45,000,000$ \\
\hline 2 & 02 Maret 2020 & KANTOR CABANG BIAK & BERAS PREMIUM $15 \%$ & 6,000 & 9,000 & $54,000,000$ \\
\hline 3 & 02 Maret 2020 & KANTOR CABANG BIAK & BERAS PREMIUM $15 \%$ & 5,000 & 9,000 & $45,000,000$ \\
\hline 4 & 02 Maret 2020 & KANTOR CABANG BIAK & BERAS PREMIUM $15 \%$ & 4,000 & 9,000 & $36,000,000$ \\
\hline 5 & 02 Maret 2020 & KANTOR CABANG BIAK & BERAS PREMIUM $15 \%$ & 5,000 & 9,000 & $45,000,000$ \\
\hline \begin{tabular}{|c|c|}
6 & \\
\end{tabular} & 06 Maret 2020 & KANTOR CABANG BIAK & BERAS PREMIUM $15 \%$ & 2,750 & 9,000 & $24,750,000$ \\
\hline $\begin{array}{ll}7 \\
\end{array}$ & 10 Maret 2020 & KANTOR CABANG BIAK & BERAS PREMIUM $10 \%$ & 1,040 & 10,500 & $10,920,000$ \\
\hline 8 & 0 Maret 2020 & KANTOR CABANG BIAK & BERAS PREMIUM $15 \%$ & 3,000 & 9,000 & $7,000,000$ \\
\hline \begin{tabular}{|l|l|l|l}
9 & & \\
\end{tabular} & 10 Maret 2020 & KANTOR CABANG BIAK & BERAS PREMIUM $15 \%$ & 2,000 & 9,000 & $18,000,000$ \\
\hline 10 & 13 Maret 2020 & KANTOR CABANG BIAK & BERAS PREMIUM $15 \%$ & 3,000 & 9,000 & $27,000,000$ \\
\hline 11 & 13 Maret 2020 & KANTOR CABANG BIAK & BERAS PREMIUM $15 \%$ & 3,000 & 9,000 & $27,000,000$ \\
\hline 12 & 17 Maret 2020 & KANTOR CABANG BIAK & BERAS PREMIUM $15 \%$ & 2,000 & 9,000 & $18,000,000$ \\
\hline 13 & 17 Maret 2020 & KANTOR CABANG BIAK & BERAS PREMIUM $15 \%$ & 3,000 & 9,000 & $27,000,000$ \\
\hline 14 & 17 Maret 2020 & KANTOR CABANG BIAK & BERAS PREMIUM $15 \%$ & 2,500 & 9,000 & $22,500,000$ \\
\hline 15 & 20 Maret 2020 & KANTOR CABANG BIAK & BERAS PREMIUM $15 \%$ & 2,000 & 9,000 & $18,000,000$ \\
\hline 16 & 20 Maret 2020 & KANTOR CABANG BIAK & BERAS PREMIUM $15 \%$ & 3,000 & 9,000 & $27,000,000$ \\
\hline 17 & 23 Maret 2020 & KANTOR CABANG BIAK & BERAS PREMIUM $15 \%$ & 3,000 & 9,000 & $27,000,000$ \\
\hline 18 & 23 Maret 2020 & KANTOR CABANG BIAK & BERAS PREMIUM $15 \%$ & 2,000 & 9,000 & $18,000,000$ \\
\hline 19 & 30 Maret 2020 & KANTOR CABANG BIAK & BERAS PREMIUM $15 \%$ & 4,000 & 9,000 & $36,000,000$ \\
\hline 20 & 30 Maret 2020 & KANTOR CABANG BIAK & BERAS PREMIUM $15 \%$ & 4,550 & 9,000 & $40,950,000$ \\
\hline 21 & 30 Maret 2020 & KANTOR CABANG BIAK & BERAS PREMIUM $15 \%$ & 4,000 & 9,000 & $36,000,000$ \\
\hline 22 & 30 Maret 2020 & KANTOR CABANG BIAK & BERAS PREMIUM $15 \%$ & 4,000 & 9,000 & $36,000,000$ \\
\hline 23 & 31 Maret 2020 & KANTOR CABANG BIAK & BERAS PREMIUM $15 \%$ & 260 & 12,000 & $3,120,000$ \\
\hline 24 & 31 Maret 2020 & KANTOR CABANG BIAK & BERAS PREMIUM $10 \%$ & 4,590 & 10,500 & $48,195,000$ \\
\hline
\end{tabular}
TOTAL VOLUME PENJUALAN 


\begin{tabular}{|c|c|c|c|c|c|c|}
\hline \multicolumn{7}{|c|}{ APRIL 2020} \\
\hline No & Tanggal Transaksi & Kantor Cabang/ Entitas & Kualitas & $\begin{array}{c}\text { Kuantum } \\
\text { Terjual (Kg) }\end{array}$ & $\begin{array}{c}\mathrm{Harga} / \mathrm{Kg} \\
(\mathrm{Rp})\end{array}$ & $\begin{array}{c}\text { VOLUME } \\
\text { PENJUALAN (Rp) }\end{array}$ \\
\hline 1 & 01 April 2020 & KANTOR CABANG BIAK & BERAS PREMIUM $15 \%$ & 4,005 & 9,800 & $39,249,000$ \\
\hline 2 & 02 April 2020 & KANTOR CABANG BIAK & BERAS PREMIUM $15 \%$ & 150 & 9,500 & $1,425,000$ \\
\hline 3 & 02 April 2020 & KANTOR CABANG BIAK & BERAS PREMIUM $10 \%$ & 20 & 9,900 & 198,000 \\
\hline 4 & 02 April 2020 & KANTOR CABANG BIAK & BERAS PREMIUM $15 \%$ & 4,000 & 9,000 & $36,000,000$ \\
\hline 5 & 02 April 2020 & KANTOR CABANG BIAK & BERAS PREMIUM $15 \%$ & 3,000 & 9,000 & $27,000,000$ \\
\hline 6 & 02 April 2020 & KANTOR CABANG BIAK & BERAS PREMIUM $15 \%$ & 3,000 & 9,000 & $27,000,000$ \\
\hline 7 & 03 April 2020 & KANTOR CABANG BIAK & BERAS PREMIUM $15 \%$ & 4,000 & 9,000 & $36,000,000$ \\
\hline 8 & 03 April 2020 & KANTOR CABANG BIAK & BERAS PREMIUM $15 \%$ & 3,000 & 9,000 & $27,000,000$ \\
\hline 9 & 03 April 2020 & KANTOR CABANG BIAK & BERAS PREMIUM $15 \%$ & 3,000 & 9,000 & $27,000,000$ \\
\hline 10 & 06 April 2020 & KANTOR CABANG BIAK & BERAS PREMIUM $15 \%$ & 954 & 9,800 & $9,349,200$ \\
\hline 11 & 06 April 2020 & KANTOR CABANG BIAK & BERAS PREMIUM $15 \%$ & 3,000 & 9,000 & $27,000,000$ \\
\hline 12 & 06 April 2020 & KANTOR CABANG BIAK & BERAS PREMIUM $15 \%$ & 4,000 & 9,000 & $36,000,000$ \\
\hline 13 & 06 April 2020 & KANTOR CABANG BIAK & BERAS PREMIUM $15 \%$ & 3,000 & 9,000 & $27,000,000$ \\
\hline 14 & 08 April 2020 & KANTOR CABANG BIAK & BERAS PREMIUM $15 \%$ & 3,000 & 9,000 & $27,000,000$ \\
\hline 15 & 08 April 2020 & KANTOR CABANG BIAK & BERAS PREMIUM $15 \%$ & 3,000 & 9,000 & $27,000,000$ \\
\hline 16 & 09 April 2020 & KANTOR CABANG BIAK & BERAS PREMIUM $15 \%$ & 4,500 & 9,000 & $40,500,000$ \\
\hline \begin{tabular}{|l|}
17 \\
\end{tabular} & 09 April 2020 & KANTOR CABANG BIAK & BERAS PREMIUM $15 \%$ & 3,000 & 9,000 & $27,000,000$ \\
\hline 18 & 09 April 2020 & KANTOR CABANG BIAK & BERAS PREMIUM $15 \%$ & 2,000 & 9,000 & $18,000,000$ \\
\hline 19 & 09 April 2020 & KANTOR CABANG BIAK & BERAS PREMIUM $15 \%$ & 2,000 & 9,000 & $18,000,000$ \\
\hline 20 & 13 April 2020 & KANTOR CABANG BIAK & BERAS PREMIUM $15 \%$ & 3,500 & 9,000 & $31,500,000$ \\
\hline \begin{tabular}{|l|}
21 \\
\end{tabular} & 13 April 2020 & KANTOR CABANG BIAK & BERAS PREMIUM $15 \%$ & 3,000 & 9,000 & $27,000,000$ \\
\hline 22 & 15 April 2020 & KANTOR CABANG BIAK & BERAS PREMIUM $15 \%$ & 10,000 & 9,000 & $90,000,000$ \\
\hline 23 & 15 April 2020 & KANTOR CABANG BIAK & BERAS PREMIUM $15 \%$ & 10,000 & 9,000 & $90,000,000$ \\
\hline 24 至 & 15 April 2020 & KANTOR CABANG BIAK & BERAS PREMIUM $15 \%$ & 10,000 & 9,000 & $90,000,000$ \\
\hline 25 & 15 April 2020 & KANTOR CABANG BIAK & BERAS PREMIUM $15 \%$ & 10,000 & 9,000 & $90,000,000$ \\
\hline 26 & 15 April 2020 & KANTOR CABANG BIAK & BERAS PREMIUM $15 \%$ & 10,000 & 9,000 & $90,000,000$ \\
\hline \begin{tabular}{|l|l|}
27 \\
\end{tabular} & 16 April 2020 & KANTOR CABANG BIAK & BERAS PREMIUM $15 \%$ & 10,000 & 9,000 & $90,000,000$ \\
\hline 28 & 16 April 2020 & KANTOR CABANG BIAK & BERAS PREMIUM $15 \%$ & 15,000 & 9,000 & $135,000,000$ \\
\hline 29 & 16 April 2020 & KANTOR CABANG BIAK & BERAS PREMIUM $15 \%$ & 15,000 & 9,000 & $135,000,000$ \\
\hline 30 & 16 April 2020 & KANTOR CABANG BIAK & BERAS PREMIUM $15 \%$ & 15,000 & 9,000 & $135,000,000$ \\
\hline 31 & 16 April 2020 & KANTOR CABANG BIAK & BERAS PREMIUM $15 \%$ & 20,000 & 9,000 & $180,000,000$ \\
\hline 32 & 17 April 2020 & KANTOR CABANG BIAK & BERAS PREMIUM $15 \%$ & 6,264 & 9,800 & $61,387,200$ \\
\hline 33 & 20 April 2020 & KANTOR CABANG BIAK & BERAS PREMIUM $15 \%$ & 15,000 & 9,000 & $135,000,000$ \\
\hline 34 & 20 April 2020 & KANTOR CABANG BIAK & BERAS PREMIUM $15 \%$ & 10,000 & 9,000 & $90,000,000$ \\
\hline 35 & 20 April 2020 & KANTOR CABANG BIAK & BERAS PREMIUM $15 \%$ & 15,000 & 9,000 & $135,000,000$ \\
\hline 36 & 20 April 2020 & KANTOR CABANG BIAK & BERAS PREMIUM $15 \%$ & 10,000 & 9,000 & $90,000,000$ \\
\hline 37 & 20 April 2020 & KANTOR CABANG BIAK & BERAS PREMIUM $15 \%$ & 5,000 & 9,000 & $45,000,000$ \\
\hline 38 & 21 April 2020 & KANTOR CABANG BIAK & BERAS PREMIUM $15 \%$ & 15,000 & 9,000 & $135,000,000$ \\
\hline 39 & 21 April 2020 & KANTOR CABANG BIAK & BERAS PREMIUM $15 \%$ & 15,000 & 9,000 & $135,000,000$ \\
\hline 40 & 21 April 2020 & KANTOR CABANG BIAK & BERAS PREMIUM $15 \%$ & 10,000 & 9,000 & $90,000,000$ \\
\hline 41 & 21 April 2020 & KANTOR CABANG BIAK & BERAS PREMIUM $15 \%$ & 10,000 & 9,000 & $90,000,000$ \\
\hline 42 & 22 April 2020 & KANTOR CABANG BIAK & BERAS PREMIUM $15 \%$ & 5,004 & 9,800 & $49,039,200$ \\
\hline 43 & 23 April 2020 & KANTOR CABANG BIAK & BERAS PREMIUM $15 \%$ & 5,000 & 9,700 & $48,500,000$ \\
\hline 44 & 23 April 2020 & KANTOR CABANG BIAK & BERAS PREMIUM $15 \%$ & 10,000 & 9,700 & $97,000,000$ \\
\hline 45 & 23 April 2020 & KANTOR CABANG BIAK & BERAS PREMIUM $15 \%$ & 10,000 & 9,700 & $97,000,000$ \\
\hline 46 & 24 April 2020 & KANTOR CABANG BIAK & BERAS PREMIUM $15 \%$ & 10,000 & 9,750 & $97,500,000$ \\
\hline 47 & 24 April 2020 & KANTOR CABANG BIAK & BERAS PREMIUM $15 \%$ & 10,000 & 9,750 & $97,500,000$ \\
\hline 48 & 24 April 2020 & KANTOR CABANG BIAK & BERAS PREMIUM $15 \%$ & 9,260 & 9,750 & $90,285,000$ \\
\hline 49 & il 2020 & KANTOR CABANG BIAK & BERAS PREMIUM $15 \%$ & 10,008 & 9,800 & $98,078,400$ \\
\hline \multicolumn{6}{|c|}{ TOTAL VOLUME PENJUALAN } & $3,342,511,000$ \\
\hline \multicolumn{7}{|c|}{ MEI 2020} \\
\hline no & Tanggal Transaksi & Kantor Cabang/ Entitas & Kualitas & $\begin{array}{l}\text { Kuantum } \\
\text { Terjual (Kg) }\end{array}$ & $\begin{array}{c}\text { Harga/Kg } \\
(\mathrm{Rp})\end{array}$ & $\begin{array}{c}\text { VOLUME } \\
\text { PENJUALAN (Rp) }\end{array}$ \\
\hline 1 & 01 Mei 2020 & KANTOR CABANG BIAK & BERAS PREMIUM $15 \%$ & 10,000 & 9,800 & $98,000,000$ \\
\hline 2 & 12 Mei 2020 & KANTOR CABANG BIAK & BERAS PREMIUM $10 \%$ & 9,000 & 10,550 & $94,950,000$ \\
\hline 3 & 12 Mei 2020 & KANTOR CABANG BIAK & BERAS PREMIUM $10 \%$ & 8,550 & 10,550 & $90,202,500$ \\
\hline 4 & 12 Mei 2020 & KANTOR CABANG BIAK & BERAS PREMIL & 8,000 & 10,550 & $84,400,000$ \\
\hline 5 & 12 Mei 2020 & KANTOR CABANG BIAK & BERAS PREMIUM $10 \%$ & 8,000 & 10,550 & $84,400,000$ \\
\hline 6 & 18 Mei 2020 & KANTOR CABANG BIAK & BERAS PREMIUM $15 \%$ & 270 & 12,000 & $3,240,000$ \\
\hline 7 & 18 Mei 2020 & KANTOR CABANG BIAK & BERAS PREMIUM $15 \%$ & 270 & 12,000 & $3,240,000$ \\
\hline 8 & 18 Mei 2020 & KANTOR CABANG BIAK & BERAS PREMIUM $10 \%$ & 5,000 & 10,550 & $52,750,000$ \\
\hline 9 & 18 Mei 2020 & KANTOR CABANG BIAK & BERAS PREMIUM $10 \%$ & 5,000 & 10,550 & $52,750,000$ \\
\hline 10 & 18 Mei 2020 & KANTOR CABANG BIAK & BERAS PREMIUM $10 \%$ & 5,000 & 10,550 & $52,750,000$ \\
\hline 11 & 20 Mei 2020 & KANTOR CABANG BIAK & BERAS PREMIUM $10 \%$ & 5,050 & 10,550 & $53,277,500$ \\
\hline 12 & 20 Mei 2020 & KANTOR CABANG BIAK & BERAS PREMIUM $10 \%$ & 5,000 & 10,550 & $52,750,000$ \\
\hline 13 & 22 Mei 2020 & KANTOR CABANG BIAK & BERAS PREMIUM $10 \%$ & 5,000 & 10,550 & $52,750,000$ \\
\hline 14 & 22 Mei 2020 & KANTOR CABANG BIAK & BERAS PREMIUM $10 \%$ & 7,800 & 10,550 & $82,290,000$ \\
\hline 15 & 22 Mei 2020 & KANTOR CABANG BIAK & BERAS PREMIUM $10 \%$ & 5,000 & 10,550 & $52,750,000$ \\
\hline 16 & 28 Mei 2020 & KANTOR CABANG BIAK & BERAS PREMIUM $15 \%$ & 418 & 12,500 & $5,225,000$ \\
\hline 17 & 28 Mei 2020 & KANTOR CABANG BIAK & BERAS PREMIUM $10 \%$ & 4,350 & 10,550 & $45,892,500$ \\
\hline \multicolumn{6}{|c|}{ TOTAL VOLUME PENJUALAN } & $961,617,5$ \\
\hline
\end{tabular}




\begin{tabular}{|c|c|c|c|c|c|c|}
\hline \multicolumn{7}{|c|}{ JUNI 2020} \\
\hline NO & Tanggal Transaksi & Kantor Cabang/Entitas & Kualitas & $\begin{array}{l}\text { Kuantum } \\
\text { Terjual (Kg) }\end{array}$ & $\begin{array}{c}\text { Harga/Kg } \\
\text { (Rp) }\end{array}$ & $\begin{array}{c}\text { VOLUME } \\
\text { PENJUALAN (Rp) }\end{array}$ \\
\hline 1 & 05 Juni 2020 & KANTOR CABANG BIAK & BERAS PREMIUM $15 \%$ & 850 & 9,500 & $8,075,000$ \\
\hline 2 & 05 Juni 2020 & KANTOR CABANG BIAK & BERAS PREMIUM $15 \%$ & 4,100 & 10,000 & $41,000,000$ \\
\hline 3 & 08 Juni 2020 & KANTOR CABANG BIAK & BERAS PREMIUM $15 \%$ & 19,566 & 9,800 & $191,746,800$ \\
\hline 4 & 08 Juni 2020 & KANTOR CABANG BIAK & BERAS PREMIUM $15 \%$ & 5,000 & 9,800 & $49,000,000$ \\
\hline 5 & 15 Juni 2020 & KANTOR CABANG BIAK & BERAS PREMIUM $10 \%$ & 800 & 10,500 & $8,400,000$ \\
\hline 6 & 23 Juni 2020 & KANTOR CABANG BIAK & BERAS PREMIUM $15 \%$ & 2,400 & 9,500 & $22,800,000$ \\
\hline 7 & 30 Juni 2020 & KANTOR CABANG BIAK & BERAS PREMIUM $15 \%$ & 270 & 12,000 & $3,240,000$ \\
\hline 8 & 30 Juni 2020 & KANTOR CABANG BIAK & BERAS PREMIUM $15 \%$ & 630 & 12,000 & $7,560,000$ \\
\hline \multicolumn{6}{|c|}{ TOTAL VOLUME PENJUALAN } & $331,821,800$ \\
\hline
\end{tabular}

Dari tabel 1 terlihat bahwa volume penjualan beras komersil Perum BULOG Kantor Cabang Biak mengalami kenaikan dan penurunan. Bisa dilihat pada bulan Januari 2020, total volume penjualan sebesar Rp. 618.184.800, mengalami penurunan pada bulan Februari 2020 sebesar Rp. 336.943.000 menjadi Rp. 281.241.800. Sebaliknya pada bulan Maret 2020, total volume penjualan sebesar Rp. 717.435 .000 mengalami kenaikan pada bulan April 2020 sebesar Rp. 2.625.076.000 menjadi Rp. 3.342.511.000.

\section{B. Perumusan Masalah}

Berdasarkan latar belakang yang dikemukakan di atas, maka dirumuskan permasalahan penelitian sebagai berikut:

1. Seberapa besar pengaruh kualitas produk dan harga terhadap volume penjualan beras premium Perum BULOG Kantor Cabang Biak?

2. Seberapa besar pengaruh kualitas produk terhadap volume penjualan beras premium Perum BULOG Kantor Cabang Biak?

3. Seberapa besar pengaruh harga terhadap volume penjualan beras premium Perum BULOG Kantor Cabang Biak?

\section{LANDASAN TEORI}

\section{A. Kajian Teori}

\section{Teori Kualitas Produk}

Menurut Kotler dan Amstrong (2008:214), kualitas produk adalah kemampuan sebuah produk dalam memperagamkan fungsinya. Kualitas produk yang baik merupakan harapan konsumen yang harus dipenuhi oleh perusahaan, karena kualitas produk yang baik merupakan kunci perkembangan produktivitas perusahaan. Indikator kualitas produk menurut Mullins et al (2005:422) apabila perusahaan ingin mempertahankan keunggulan kompetetifnya dalam pasar, perusahaan harus mengerti aspek dimensi apa saja yang digunakan oleh konsumen untuk membedakan produk yang dijual perusahaan tersebut dengan produk pesaing, indikator dari kualitas produk terdiri dari:

a. Performance (kinerja), berhubungan dengan karakteristik operasi dasar dari sebuah produk. kinerja merupakan karakteristik atau fungsi utama suatu produk. Ini merupakan manfaat atau khasiat utama produk yang kita beli. biasanya ini menjadi pertimbangan pertama kita membeli produk.

b. Durability (daya tahan), yang berarti berapa lama atau umur produk yang bersangkutan bertahan sebelum produk tersebut harus diganti, semakin besar frekuensi pemakaian konsumen terhadap produk maka semakin besar pula daya tahan produk.

c. Comformance to specifications (kesesuaian dengan spesifikasi), yaitu sejauh mana karakteristik operasi dasar dari sebuah produk memenuhi spesifikasi tertentu dari konsumen atau tidak ditemukannya cacat pada produk.

d. Features (fitur) adalah karakteristik produk yang dirancang untuk menyempurnakan fungsi produk atau menambah ketertarikan konsumen terhadap produk Dimensi fitur merupakan karakteristik atau ciri-ciri tambahan yang melengkapi manfaat dasar suatu produk. Fitur bersifat pilihan atau option bagi konsumen. 
Menurut Kotler dalam Arumsari (2012:44), kebanyakan produk disediakan pada satu diantara empat tingkatan kualitas, yaitu : kualitas rendah, kualitas rata-rata atau sedang, kualitas baik dan kualitas sangat baik. Dimana beberapa dari atribut diatas dapat diukur secara objektif.

\section{Teori Volume Penjualan}

Teori Volume Penjualan adalah barang yang terjual dalam bentuk uang untuk jangka waktu tertentu yang di dalamnya mempunyai strategi pelayanan yang baik (Kotler, 2000:68). Semakin besar jumlah penjualan yang dihasilkan perusahaan, semakin besar kemungkinan laba yang dihasilkan perusahaan. Oleh karena itu volume penjualan merupakan salah satu hal penting yang harus dievaluasi untuk kemungkinan perusahaan agar tidak rugi. Jadi volume penjualan yang menguntungkan harus menjadi tujuan utama perusahaan dan bukannya untuk kepentingan volume penjualan itu sendiri. Volume penjualan dihitung berdasarkan target yang diasumsikan dengan realisasi yang dicapai. Volume penjualan tidak memisahkan secara tunai maupun kredit, tetapi dihitung secara keseluruhan dari total yang dicapai. Maka kalau volume penjualan meningkat dan biaya distribusi menurun maka tingkat pencapaian laba perusahaan meningkat. Tetapi sebaliknya bila volume penjualan menurun maka pencapaian laba perusahaan menurun. penjualan yang dicapai dari market share (pangsa pasar) yang merupakan penjualan potensial yang dapat terdiri dari kelompok pembeli selama jangka waktu tertentu. Terdapat beberapa indikator dari volume penjualan yang dikutip dari Kotler oleh Swastha dan Irawan (2003:404) yaitu:
a. Mencapai volume penjualan
b. Mendapatkan laba
c. Menunjang pertumbuhan perusahaan

\section{Hipotesis}

Berdasarkan model penelitian maka hipotesis dari penelitian ini adalah sebagai berikut.

$\mathrm{H} 1$ : Kualitas produk dan harga, diduga berpengaruh secara bersama terhadap volume penjualan.

$\mathrm{H} 2$ : Kualitas produk diduga berpengaruh terhadap volume penjualan.

H3: Harga diduga berpengaruh terhadap volume penjualan.

\section{METODE PENELITIAN}

\section{A. Lokasi, Sumber Data dan Jenis Penelitian}

Penelitian ini dilakukan di kantor Perum BULOG Cabang Biak yang beralamat di Jl. Dolog Biak No. 14, Kelurahan, Distrik Biak Kota, Kabupaten Biak Numfor.Penelitian ini, penulis menggunakan pendekatan deskriptif kuantitatif yaitu penelitian dengan menekankan analisisnya pada data - data numerikal (angka) yang diolah dengan metode statistika, yaitu data - data kuantitatif yang dikumpulkan melalui pengukuran, sedangkan sumber data berupa data sekunder.

\section{B. Populasi, Sampel dan Teknik Pengambilan Sampel}

Populasi dalam penelitian ini adalah laporan penjualan komoditi di Perum BULOG Kantor Cabang Biak. Kriteria pemilihan sampel adalah laporan penjualan beras premium komersil di Perum BULOG Kantor Cabang Biak Bulan Januari 2020 sampai dengan bulan Juni 2020

\section{HASIL DAN PEMBAHASAN}

\section{A. Deskripsi Data}

\section{Uji Asumsi Klasik}

Uji Asumsi klasik adalah analisis yang dilakukan untuk menilai apakah di dalam sebuah model regresi linear Ordinary Least Square (OLS) terdapat masalah-masalah asumsi klasik. Berikut adalah beberapa uji asumsi klasik yang dilakukan antara lain : 


\section{a. Uji Normalitas}

Uji Normalitas adalah uji statistik yang dilakukan untuk mengetahui bagaimana sebaran sebuah data. Menurut Ghozali (2011:161) model regresi dikatakan berdistribusi normal jika data ploting (titik - titik) yang menggambarkan data sesungguhnya mengikuti garis diagonal

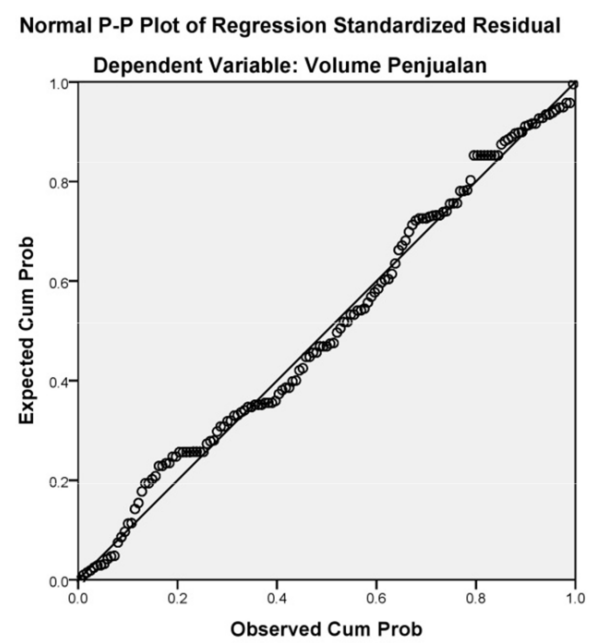

Gambar 1. P-Plot Regresi Linier

Berdasarkan gambar 1 di atas dapat dilihat bahwa data ploting atau titik - titik data yang menggambarkan data ses ungguhnya mengikuti garis diagonal, sehingga dapat disimpulkan model regresi berdistribusi normal.

\section{b. Uji Multikoleniaritas}

Multikolinearitas adalah sebuah situasi yang menunjukkan adanya korelasi atau hubungan kuat antara dua variabel bebas atau lebih dalam sebuah model regresi berganda. Menurut Ghozali (2011: 107-108) tidak terjadi gejala multikolineritas, jika nilai tolerance $>0,100$ dan nilai VIF $<10,00$.

\section{Tabel 2. Tabel Coefficients a Collinearity Statistics}

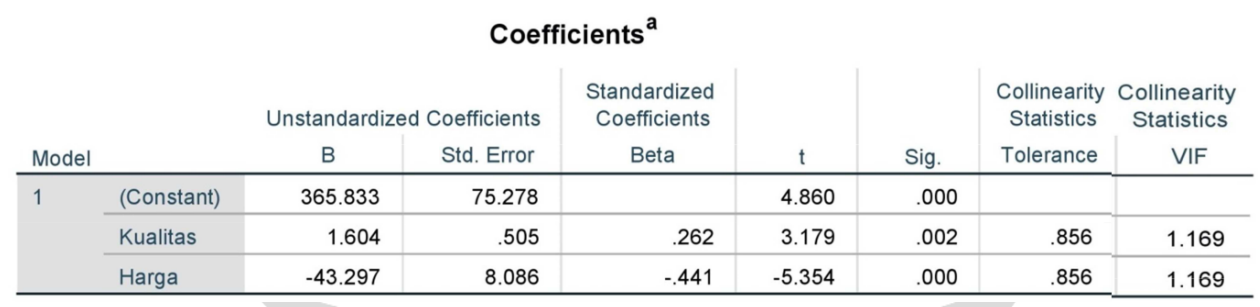

Berdasarkan tabel 2 di atas bisa dilihat nilai tolerance 0,856 atau nilai tolerance $>0,100$ dan nilai VIF 1,169 atau VIF $<10,00$, jadi dapat disimpulkan bahwa antara kedua variabel bebas yakni kualitas dan harga tidak ada gejala multikoliniearitas.

\section{c. Uji Heteroskedastisitas}

Uji Heteroskedastisitas adalah uji yang menilai apakah ada ketidaksamaan varian dari residual untuk semua pengamatan pada model regresi linear. Menurut Ghozali (2011: 139) tidak terjadi heteroskedastisitas, jika tidak ada pola yang jelas (bergelombang, melebar kemudian menyempit) pada gambar scatterplots, serta titik - titik menyebar di atas dan di bawah angka 0 pada sumbu $Y$. 


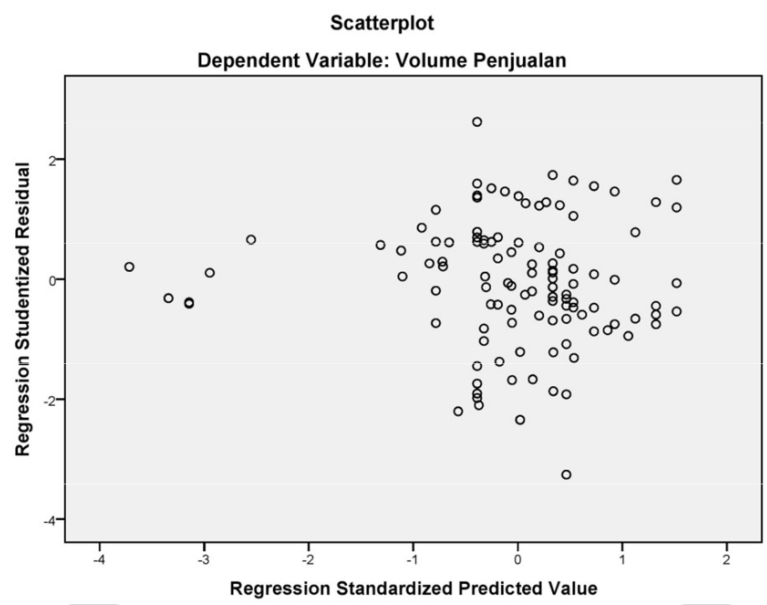

Gambar 2 Gambar Scatterplot

Berdasarkan gambar 2 di atas dapat kita lihat tidak ada pola yang jelas (bergelombang, melebar kemudian menyempit), serta titik - titik menyebar di atas dan di bawah angka 0 pada sumbu $Y$, sehingga dapat disimpulkan tidak ada gejala heteroskedastisitas

\section{d. Uji Autokorelasi}

Uji Autokorelasi adalah sebuah analisis statistik yang dilakukan untuk mengetahui adakah korelasi variabel yang ada di dalam model prediksi dengan perubahan waktu. Menurut Ghozali (2011: 111) tidak ada gejala autokorelasi, jika nilai Durbin Watson terletak antara du sampai dengan (4-du). Nilai du dicari pada distribusi nilai tabel durbin Watson berdasarkan $\mathrm{k}(2)$ dan N (145) dengan signifikansi $5 \%$, maka nilai Durbin Watson adalah 1,756 .

\begin{tabular}{|c|c|c|c|c|c|}
\hline \multicolumn{6}{|c|}{ Model Summary ${ }^{b}$} \\
\hline Model & $\mathrm{R}$ & R Square & $\begin{array}{l}\text { Adjusted R } \\
\text { Square }\end{array}$ & $\begin{array}{l}\text { Std. Error of the } \\
\text { Estimate }\end{array}$ & Durbin-Watson \\
\hline 1 & $.664^{\mathrm{a}}$ & .440 & .436 & 13.24650224 & 2.002 \\
\hline
\end{tabular}

Berdasarkan tabel 3 dapat dilihat nilai du $(1,756)<$ Durbin Watson $(2,002)<4$ - du $(2,244)$ sehingga dapat disimpulkan tidak terjadi gejala autokorelasi.

\section{B. Pengujian Hipotesis}

\section{Uji Signifikansi Simultan}

Menurut Ghozali (2011: 101) jika nilai Sig < 0,05 maka artinya variabel independent $(X)$ secara simultan berpengaruh terhadap variabel dependent $(Y)$. 
Tabel 4. Tabel Anova ${ }^{a}$ Uji F Simultan

\begin{tabular}{|c|c|c|c|c|c|c|}
\hline \multicolumn{7}{|c|}{ ANOVA $^{a}$} \\
\hline Model & & $\begin{array}{l}\text { Sum of } \\
\text { Squares }\end{array}$ & df & Mean Square & $\mathrm{F}$ & Sig. \\
\hline \multirow[t]{3}{*}{1} & Regression & 9491.017 & 2 & 4745.509 & 15.098 & $.000^{\mathrm{b}}$ \\
\hline & Residual & 44632.160 & 142 & 314.311 & & \\
\hline & Total & 54123.177 & 144 & & & \\
\hline
\end{tabular}

a. Dependent Variable: Volume Penjualan

b. Predictors: (Constant), Harga, Kualitas

Berdasarkan tabel 4 dapat dilihat nilai signifikansi $F$ adalah $0,000<0,05$ hal ini menunjukkan bahwa variabel independent Kualitas (X1) dan Harga (X2) secara simultan berpengaruh terhadap variabel dependent Volume Penjualan (Y), sehingga dapat disimpulkan bahwa Hipotesis 1 (H1) diterima. Hasil penelitian ini mendukung penelitian sebelumnya yang dilakukan oleh Mufidah (20017:9-10), Mokalu dan Tumbel (2015:263), Hartanto (2014: 15-16), Ismayana dan Hayati (2018:12-13), Agustina dan Sunrowiyati (2016:111-112).

\section{Uji Signifikansi Parameter Individual (Uji Statistik t)}

Menurut Ghozali (2011: 101) jika nilai Sig < 0,05 maka artinya varibel independentt $(X)$ secara parsial berpengaruh terhadap variabel dependent (Y).

\section{Tabel 5. Tabel Coefficients a Uji t Parsial Coefficients $^{\mathrm{a}}$}

\begin{tabular}{|c|c|c|c|c|c|c|}
\hline \multirow[b]{2}{*}{ Model } & & \multicolumn{2}{|c|}{ Unstandardized Coefficients } & \multirow{2}{*}{$\begin{array}{c}\text { Standardized } \\
\text { Coefficients } \\
\text { Beta } \\
\end{array}$} & \multirow[b]{2}{*}{$t$} & \multirow[b]{2}{*}{ Sig. } \\
\hline & & $\mathrm{B}$ & Std. Error & & & \\
\hline \multirow[t]{3}{*}{1} & (Constant) & 365.833 & 75.278 & & 4.860 & .000 \\
\hline & Kualitas & 1.604 & .505 & .262 & 3.179 & .002 \\
\hline & Harga & -43.297 & 8.086 & -.441 & -5.354 & .000 \\
\hline
\end{tabular}

Berdasarkan tabel 5 dapat dilihat nilai signifikansi t variabel independent Kualitas adalah $0,002<0,05$ hal ini menunjukkan bahwa variabel independent Kualitas (X1) secara parsial berpengaruh terhadap variabel dependent Volume Penjualan (Y), sehingga dapat disimpulkan bahwa Hipotesis $2(\mathrm{H} 2)$ diterima. Hasil penelitian ini mendukung penelitian sebelumnya yang dilakukan oleh Mufidah (20017:9-10), Mokalu dan Tumbel (2015:263), Hartanto (2014: 15-16), Ismayana dan Hayati (2018:12-13), Agustina dan Sunrowiyati (2016:111-112). Dalam tabel 5 juga dapat dilihat nilai signifikansi t variabel independent Harga (X2) adalah $0,000<0,05$ hal ini menunjukkan bahwa variabel independent Harga (X2) secara parsial berpengaruh terhadap variabel dependent Volume Penjualan (Y), sehingga dapat disimpulkan bahwa Hipotesis 3 (H3) diterima. 


\section{PENUTUP}

\section{A. Simpulan}

Beberapa kesimpulan dari penelitian ini dapat dijelaskan sebagai berikut:

1. Kualitas Produk dan Harga secara simultan berpengaruh terhadap Volume Penjualan dimana angka signifikansi sebesar 0,000 lebih kecil dari tingkat signifikansi 0,05

2. Kualitas Produk secara parsial berpengaruh terhadap Volume Penjualan dimana angka signifikansi sebesar 0,002 lebih kecil dari tingkat signifikansi 0,05,

3. Harga secara parsial berpengaruh terhadap Volume Penjualan dimana angka signifikansi sebesar 0,000 lebih kecil dari tingkat signifikansi 0,05 .

\section{B. Saran}

Berdasarkan kesimpulan di atas, maka penulis memberikan saran dalam penelitian ini antara lain:

1) Penelitian selanjutnya yang sama dengan penelitian ini diharapkan dapat menambah ukuran sampel.

2) Penelitian selanjutnya dapat menggunakan terlebih dahulu pendekatan kualitatif untuk lebih mendapatkan gambaran perilaku yang lebih jelas.

\section{DAFTAR PUSTAKA}

[1]. Agustina, Sari dan Siti Sunrowiyati (2016), Analisis Faktor Kualitas Produk dan Harga Guna Meningkatkan Volume Penjualan Pada Usaha Genteng UD Super Blitar. Jurnal Penelitian Manajemen Terapan (PENATARAN), Vol. 1, No. 1, 2016, hal. 104-114

[2]. Arumsari, Dheany (2012), Analisis Pengaruh Kualitas Produk, Harga dan Promosi Keputusan Pembelian Air Minum Dalam Kemasan (AMDK) Merek AQUA. Skripsi. Semarang: Universitas Diponegoro.

[3]. Bulog (2012), Kebijakan Pengadaan Gabah dan Beras, Jakarta: Instruksi Presiden Nomor 3

[4]. Bulog (2014), Peraturan Pergudangan Di Lingkungan Perum Bulog Tahun 2014. Jakarta: Perum Bulog

[5]. Ghozali, Imam (2011), Aplikasi Analisis Dengan Program SPSS, Semarang: Badan Penerbit Universitas Diponegoro

[6]. Hartanto, Andi (2014), Pengaruh Kualitas Produk, Periklanan dan Harga Terhadap Volume Penjualan Pada Onsight Outdoor Equipmentt, Naskah Publikasi Universitas Muhammadiyah Surakarta, hal. 1-17

[7]. Irawan (2005), Analisis Ketersediaan Beras Nasional Suatu Kajian Simulasi Pendekatan Sistem Dinamis. Prosiding Multifungsi Pertanian, ISBN: 979-9474-42-6

[8]. Ismayana, Sari dan Nur Hayati (2018), Pengaruh Kualitas Produk dan Harga Terhadap Keputusan Pembelian Produk Lipstik Pixy Studi Pada konsumen Produk Lipstik Pixy Toserba Borma Cipadung, Jurnal Sains Manajemen \& Akuntansi STIE-STAN IM, Vol. X, No. 2, November 2018, hal. 1-15

[9]. Kotler, Philip (2000), Prinsip-Prinsip Pemasaran Manajemen, Jakarta:Prehalindo

[10]. Kotler, Philip dan Gary Amstrong (2008), Prinsip-Prinsip Pemasaran, Jilid. 1 dan 2, Ed. 12, Jakarta: Erlangga

[11]. Mokalu, Frendy $O$ dan Altje Tumbel (2015), Pengaruh Kualitas Produk Harga dan Distribusi Terhadap Volume Penjualan Rori Jordan CV. Minahasa Mantap Perkasa, Jurnal EMBA, Vol. 3, No. 1, ISSN: 2303-1174, hal: 254-265

[12]. Mufidah, Ratih Asri (2017), Pengaruh Kualitas Produk Dan Harga terhadap Volume Penjualan Beras Premium Perum Bulog Sub Divisi Regional Wilayah V Kedu, Makalah Jurnal Program Studi S1 Agribisnis Fakultas Peternakan dan Pertanian Universitas Diponegoro, Semarang: Universitas Diponegoro

[13]. Mullin, John W, dan Orville C Walker (2005), Marketing Management a Strategic Decision, $5^{\text {th }}$ Edition, New York: McGraw Hill

[14]. Perum Bulog (2012), Sejarah Perum Bulog, www.bulog.co.id

[15]. Perum Bulog (2015), Standar Operasional Prosedur Pengadaan Gabah/Beras Dalam Negeri Di Perum Bulog Tahun 2015. Jakarta: Perum Bulog

[16]. Silsia, M (2007), Analisis Peranan Perusahaan Umum Bulog Sub Divisi Regional Bukit Tinggi Dalam Mengendalikan Harga Gabah Dan Beras Pada Wilayah Kerjanya. Skripsi, Padang: Universitas Andalas.

[17]. Swasta, Basu dan Irawan (2003), Manajemen Pemasaran Modern, Ed. 2, Cetakan 11, Yogyakarta: Liberty Offset. 